\title{
An Investigation on the Effectiveness of Virtual Experiential Learning (VEL) for Educating Undergraduate Students on Traffic Rules in Thailand
}

\author{
Sirilak Borirug and Chun Che Fung
}

\begin{abstract}
Road traffic accidents have become a major health problem worldwide. There is an urgent need to educate young drivers on road safety and traffic rules. This study aims to investigate the effectiveness of Virtual Experiential Learning (VEL) for educating undergraduate students on traffic rules in Thailand. The results showed that the VEL affected cognitive load reduction in both short term and long term memory which can increase student's knowledge in traffic rules efficiently.
\end{abstract}

Index Terms-Cognitive load reduction, experiential learning, multimedia learning.

\section{INTRODUCTION}

Nowadays, road traffic injury is the number one cause of death for young people worldwide [1]. The Department of Violence and Injury Prevention and Disability (VIP) of World Health Organization (WHO) reported that there are 1.3 million road deaths in the world each year, and the figure is forecasted to increase to 1.9 million by 2020 [1]. In Thailand, the Ministry of Public Health is aware that road accidents is one of the top three public health problems in the country. The costs of property damages due to road accidents and associated losses are estimated to be more than 232,000 million Baht annually [2]. The economy losses from road accidents include medical costs for human, property damages, and general costs due to vehicle crashes. From these aspects, the Ministry of Transportation of Thailand has established a national policy to educate the drivers and the main target group is the younger population. The age group between 15 to 29 years has the highest death rate due to road traffic accidents as reported by the department of VIP [1]. It is understandable that this demographic group, due to their age, has limited driving experience, skills and knowledge [3]. A comprehensive road safety master plan has been developed in Thailand in order to educate the young drivers on road safety. The aim is to reduce the number of crashes and injuries resulted from the accidents [4].

\section{A. Cognitive Load Theory and Information technology}

Cognitive Load Theory (CLT) is a learning process comprises of learning, memorizing, and problem solving [5]. It concerns with three distinct types of memory which are: sensory, working (short term), and long term memory. The working memory is the main processor of the brain and

Manuscript received September 25, 2012: revised October 15, 2012.

The authors are with the School of Information Technology, Murdoch University, Australia (e-mail: si_bori2002@yahoo.com, 1.fung@murdoch.edu.au). establishes knowledge when it combines prior knowledge with information from the sensory memory [6]. Then, the information will be established and retained in the long term memory.

Information Technology (IT) has shown that it is able to play an important role to increase the effectiveness and efficiency of various instructional design strategies [7]. The advantages of IT have manifolds such as the providence of many forms of presentations that could be used to develop various modes learning instructions in order to solve the problem of cognitive overload [7], [8].

IT enables the utilization of multi sensory channels to convey various forms of information from the learning system to the learners. However, working memory has limited capacity, presenting too much information via too many channels may cause missed important information during learning [9]. This may result in the learner ignoring the content in the process. Hence, the challenge is how to utilize the technology to develop an optimal learning system. Course designers and researchers need to understand and balance the loading onto the learner between these three types of memory in order to ensure that knowledge will be established in the long term memory. This research aims to investigate the effectiveness of learning instructions designed with Experiential Learning with respect to cognitive load reduction on the education of undergraduate students on traffic rules.

\section{Current Solutions}

Instructional technology utilized in the form of Multimedia instructions have the capacity to offer powerful presentation to students and learners [10]. There have been many studies aimed to solve the problem of cognitive overload using multimedia teaching materials. However, multimedia learning has associated problems that inhabit the achievement of the best outcome. Research on solving the representation of multi-channel in multimedia environment has been studied in a number of projects. Educational interfaces based on human computer interaction and instructional design have also studied under the user-centered design principles for cognitive load reduction [11], [12]. Moreover, Cognitive Load Theory has been developed to investigate the influences on learning achievement under various multimedia combinations and learner-controlled modes [13]. Multifunctional websites that provide teaching resources, interesting experiments, inquiry experiments, virtual animations, multi-assessments, and supplementary 
materials, haves shown to be highly interactive and simulative. The study has found that learner-controlled modes were significantly influential and various multimedia combinations have brought apparent influences on learning effects[13]. A presentation method of Dual Channel model wsa investigated and the efficiency of resource allocation of cognitive memory capacity was reported to be increased [14]. The channels convey visual contents such as text and images, combined with synchronization of narration such as sound content and a pointer. The result showed the validity of this model and the effectiveness of the proposed content development method in e-learning. [14]

\section{RESEARCH QUESTIONS AND HYPOTHESES}

This study aims to investigate the effectiveness of learning instructions designed with Experiential Learning in cognitive load reduction on the education of undergraduate students on traffic rules. The research questions and associated hypotheses are listed below.

\section{A. Does Experiential Learning Affect Cognitive Load} Reduction on The Learning of Traffic Rules by Thai Youths in Short Term Memory?

1) Hypothesis 1: There will be no significant difference between the mean score of the post-test of traditional instructions delivered with Experiential Learning and the mean score of the post-test of traditional instructions delivered without Experiential Learning. $\left(\mathrm{H}_{1}: \mu_{\mathrm{B}}=\mu_{\mathrm{A}}\right)$

2) Hypothesis 2: There will be no significant difference between the mean score of the post-test of multimedia instructions delivered with Experiential Learning and the mean score of the post-test of traditional instructions delivered without Experiential Learning. $\left(\mathrm{H}_{2}: \mu_{\mathrm{C}}=\mu_{\mathrm{A}}\right)$

3) Hypothesis 3: There will be no significant difference between the mean score of the post-test of 3D based video instructions delivered with Experiential Learning and the mean score of the post-test of traditional instructions delivered without Experiential Learning. $\left(H_{3}: \mu_{D}=\mu_{A}\right)$

4) Hypothesis 4: There will be no significant difference between the mean score of the post-test of traditional instructions delivered with Experiential Learning, multimedia instructions delivered with Experiential Learning, and 3D based video instructions delivered with Experiential Learning and the mean score of the post-test of traditional instructions delivered without Experiential Learning. $\left(H_{4}: \mu_{\text {Average }(D, C, B)}=\mu_{A}\right)$

\section{B. Does Experiential Learning Affect Cognitive Load} Reduction on The Learning of Traffic Rules by Thai Youths in Long Term Memory?

1) Hypothesis 5: There will be no significant difference between the mean score of the final-test of traditional instructions delivered with Experiential Learning and the mean score of the final-test of traditional instructions delivered without Experiential Learning. $\left(H_{5}: \mu_{B}=\mu_{A}\right)$

2) Hypothesis 6: There will be no significant difference between the mean score of the final-test of multimedia instructions delivered with Experiential Learning and the mean score of the final-test of traditional instructions delivered without Experiential Learning. $\left(H_{6}: \mu_{C}=\mu_{A}\right)$

3) Hypothesis 7: There will be no significant difference between the mean score of the final-test of 3D based video instructions delivered with Experiential Learning and the mean score of the final-test of traditional instructions delivered without Experiential Learning. $\left(H_{7}: \mu_{D}=\mu_{A}\right)$

4) Hypothesis 8: There will be no significant difference between the mean average score of the final-test of traditional instructions delivered with Experiential Learning, multimedia instructions delivered with Experiential Learning, and 3D based video instructions delivered with Experiential Learning and the mean score of the final-test of traditional instructions delivered without Experiential Learning. $\left(H_{8}: \mu_{\text {Average }}\right.$ $\left.(D, C, B)=\mu_{A}\right)$

\section{Methodology}

This study proposes Virtual Experiential Learning (VEL) which is virtual learning based Experiential Learning techniques in a framework comprises with various modes of learning instructions[15]. These learning instructions are a) traditional learning instructions, b) multimedia instructions, and c) $3 D$ based video instructions via the Internet [15]. Experiential learning (EL) is the process of learning by doing and processing an activity, and it is related to the knowledge, skill, and practice obtained from the participation or engagement in an activity [16]. Thus, the use of VEL is to assist the learner to retrieve information in order to rethink or reorganize the working memory as shown in Fig. 1. This is because retrieval process plays a major role in helping to recall information enabling to increase the efficiency of the storage processes [17]. Moreover, the learner will be provided lessons, practices, and examples in the virtual world that learner can access to the learning system anywhere and anytime.

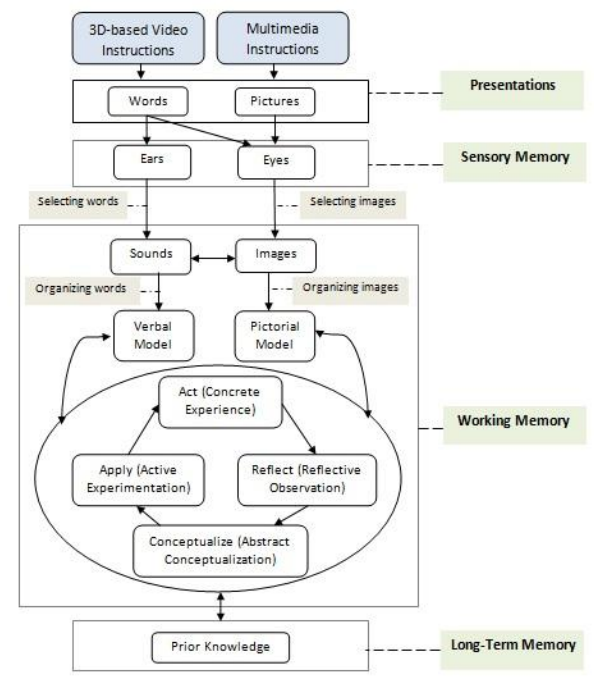

Fig. 1. The propose of VEL framework for cognitive load reduction [15]

This study has four different instructional designs and they present the same contents as shown in Table I. The control group (group A) is presented with traditional instruction 
design comprised text and pictures. Three other experiment groups are presented with traditional instruction design with EL comprised narration of text, and pictures (group B); multimedia instruction design with EL comprised narration of text, pictures, sounds, and 2D animations (group C); and 3D based instruction design with EL comprised of narration of text, pictures, sounds, and 3D videos (group D).

TABLE I: PROPOSED CONCEPTUAL FRAMEWORK FOR COGNITIVE LOAD REDUCTION

\begin{tabular}{lll}
\hline \hline Content Designs & With EL & Without EL \\
\hline Text and Pictures (control group) & & Group A \\
Text and Pictures & Group B & \\
Multimedia Instructions & Group C & \\
3D Based Video Instructions & Group D & \\
\hline \hline
\end{tabular}

The pre-test post-test, and final-test experimental design were employed in this study and the tests contained 30 questions and it takes approximately 15 minutes to complete each test. The lessons take about 30 minutes on each topic being represented by the respective instruments. The participants have to finish the pre-test and the results of four groups are compared in order to assess their knowledge background. Then, the participants take the lesson and then followed by the post-test.The parricipants were invited to finish another final-test two weeks after finished the post-test. This is aimed to assess the effectiveness of their knowledge stored in the participants' long term memory.

\section{RESEARCH RESULTS}

400 participants took part and they were undergraduate students from different universities in Thailand. 100 participants were randomly selected and allocated to each group and they were required to complete the questionnaires in this study. All the participants have no driver licenses and the participants' ages range from 18 to of 25 years. They were also chosen with similar knowledge background on traffic rules as illustrated by the mean average score of the pre-test as shown in Table II.

TABLE II: SUMMARY OF THE MEAN SCORE OF THE TESTS

\begin{tabular}{cccc}
\hline \hline Group & $\begin{array}{c}\text { Mean of the } \\
\text { Pre-test }\end{array}$ & $\begin{array}{c}\text { Mean of the } \\
\text { Post-test }\end{array}$ & $\begin{array}{c}\text { Mean of the } \\
\text { Final-Test }\end{array}$ \\
\hline A & 10.99 & 18.28 & 16.86 \\
B & 11.01 & 20.95 & 17.80 \\
C & 10.98 & 24.19 & 19.71 \\
D & 10.89 & 23.48 & 21.06 \\
\hline \hline
\end{tabular}

To analyze and test hypotheses, a two group post-test and final-test experimental design was employed in this study. SPSS was used to analyze the data, and the Independent Sample T-Test was used to prove the significance of the variables as shown in Table III.

As presented in Table II, the mean score of the post-test of the experiments group $(\mathrm{B}, \mathrm{C}, \mathrm{D})$ were higher than the control group (A). The results found that hypotheses 1 to 4 of research question 1 were rejected significantly at the 0.05 level (see Table III). This shows that the EL affected cognitive road reduction and it enabled an increase of knowledge on traffic rules in all learning instructions for short term memory. Moreover, the EL was examined against the effectiveness in long term memory with the final-test, and the results showed the mean score of the learning instructions with the EL were higher than the learning instruction without the EL. The hypotheses 5 to 8 were rejected with level of significance $\alpha=.05$. This showed that the EL affected cognitive load reduction in long term memory.

TABLE III: RESULTS OF THE INDEPENDENT SAMPLE T-TEST

\begin{tabular}{|c|c|c|c|c|c|c|}
\hline \multirow[t]{2}{*}{$\begin{array}{l}\text { Research } \\
\text { Question }\end{array}$} & \multirow[t]{2}{*}{ Hypotheses } & \multicolumn{2}{|c|}{$\begin{array}{l}\text { Levene's } \\
\text { Test for } \\
\text { Equality of } \\
\text { Variances }\end{array}$} & \multirow[t]{2}{*}{$\mathrm{t}$} & \multirow[t]{2}{*}{$\mathrm{df}$} & \multirow[t]{2}{*}{$\begin{array}{c}\text { Sig } \\
\text { (2-tailed) }\end{array}$} \\
\hline & & $\mathrm{F}$ & Sig & & & \\
\hline \multirow{4}{*}{1} & 1 & 1.14 & $\begin{array}{c}.28 \\
7\end{array}$ & -8.29 & 198 & .000 \\
\hline & 2 & 1.51 & $\begin{array}{c}.22 \\
0\end{array}$ & -20.42 & 198 & .000 \\
\hline & 3 & .014 & $\begin{array}{c}.90 \\
5 \\
\end{array}$ & -16.79 & 198 & .000 \\
\hline & 4 & $\begin{array}{c}25.5 \\
3 \\
\end{array}$ & $\begin{array}{c}.00 \\
0\end{array}$ & -18.39 & 198 & .000 \\
\hline \multirow{4}{*}{2} & 5 & 1.21 & $\begin{array}{c}.27 \\
2 \\
\end{array}$ & -2.35 & 198 & .020 \\
\hline & 6 & 3.81 & $\begin{array}{c}.05 \\
2 \\
\end{array}$ & -7.41 & 198 & .000 \\
\hline & 7 & .083 & $\begin{array}{c}.77 \\
3 \\
\end{array}$ & -9.83 & 198 & .000 \\
\hline & 8 & $\begin{array}{c}38.3 \\
1\end{array}$ & $\begin{array}{c}.00 \\
0\end{array}$ & -7.92 & 198 & .000 \\
\hline
\end{tabular}

\section{CONCLUSION AND Future WORK}

This paper presented an investigation of the effectiveness of four learning instructions designed with EL in order to support cognitive load reduction on educating traffic rules for undergraduate students in Thailand. The results examined the mean scores of the pre-test, post-test, and final-test. The result showed that learning instructions designed with EL is able to support cognitive load reduction in both short term and long term. The next step of this study will investigate the effectiveness and efficiency of each learning instructional design strategies with EL. This study supports cognitive load reduction and will contribute towards better understand on improvement of education of undergraduate students on traffic rules and it is hoped that this will lead to decrease of road traffic accidents.

\section{REFERENCES}

[1] Global status report on road safety: time for action, Geneva: World Health Organization, Department of Violence \& Injury Prevention \& Disability (VIP), 2009.

[2] Depart of Land Transport. (2011). [Online]. Available: http://www.dlt.go.th/

[3] Progress Report No.1: Road Safety Knowledge Development and Dissemination. (2011). Thailand Accident Research Center (TARC) [Online]. Available: http://www.tarc.ait.ac.th/download/eng/ProgressReport1_en.pdf

[4] Decade of Action for Road Safety. (2012). [Online]. Available: http://www.thaincd.com/document/file/activity/ (3) _ word-Pdf.pdf.

[5] J. Sweller, "Evolutionary bases of human cognitive architecture: implications for computing education," The Fourth international Workshop on Computing Education Research, 2008.

[6] W. Schnotz and C. Kürschner, "A Reconsideration of Cognitive Load Theory," Educational Psychology Review, vol. 19, pp. 469-508, 2007.

[7] R. E. Mayer and R. Mereno, "Nine ways to Reduce Cognitive Load in Multimedia Learning," Educational Psychologist, vol. 38, pp. 43-52, 2003. 
[8] X. Aidi, "Cognitive Overload and Its Countermeasures from the Angle of Information Processing," The Third International Symposium on Intelligent Information Technology Application pp. 391-394, 2009.

[9] P. Karr-Wisniewski and Y. Lu, "When More is Too Much: Operationalizing technology overload and exploring its impact on knowledge worker productivity," Computers in Human Behavior, vol. 26, pp. 1061-1072, 2010.

[10] K. A. Austin, "Multimedia learning: Cognitive individual differences and display design techniques predict transfer learning with multimedia learning modules," Computer Education, vol. 53, pp. 1339-1354, 2009.

[11] F. Pass, A. Renkl, and J. Sweller, "Cognitive Load Theory and Instructional Design: Recent Developments," Educational Psychologist, vol. 38, pp. 1-4, 2003.

[12] S. Oviatt, "Human-centered design meets cognitive load theory: designing interfaces that help people think," presented at the 14th annual ACM international conference on Multimedia, 2006.

[13] C. J. Liu, Y. C. Lin, B. Y. Liu, and Y. Y. Chang, "A Research of Applying Cognitive Load Theory to Science Education Webpage," presented at IEEE 12th International Conference on Advanced Learning Technologies (ICALT), 2012, pp. 77-79.

[14] M. Ando and M. Ueno, "Cognitive Load Reduction on Multimedia E-Learning Materials," presented at Advanced Learning Technologies, 2008. ICALT '08. Eighth IEEE International Conference on, 2008, pp. 268-272.

[15] S. Borirug, L. C. C. Fung, and W. Philuek, "A Proposed Framework of the Effectiveness of Virtual Experiential Learning (VEL) for Cognitive Load Reduction on Educating Thai Youths on Traffic Rules" Journal of Education, Chiang-Mai University vol. 38, pp. 80-88, July-December 2011

[16] D. A. Kolb. Experience Based Learning Systems, Inc.. (2011). [Online] Available: http://www.learningfromexperience.com/.

[17] Y. Cao and H. Liu, "Study of Experiential Learning as a Model for Teaching and Learning," The Second International Symposium on Knowledge Acquisition and Modeling, vol. 2, pp. 391-394, Nov-Dec., 2009.

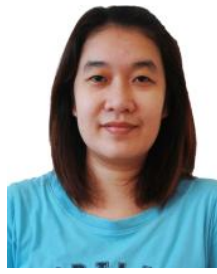

Sirilak Borirug was born in Thailand. She received a Bachelor of Arts in the University of the Thai Chamber of Commerce, Bangkok, Thailand and a Master of Information and Communication Technology in Wollongong University, New South Wales, Australia in 1993 and 2002 respectively. Since 2008 she has been a PhD student in Murdoch University, Western Australia. She had worked as a lecturer at North Bangkok University, Bangkok, Thailand in 2003 to 2006 and Nakhon Pathom Rajabhat University, Nakhon Pathom, Thailand in 2008. She has published seven international conference proceedings and one local Journal in Thailand. Her special field of interest is the implementation of Information Technology in Cognitive Load Theory.

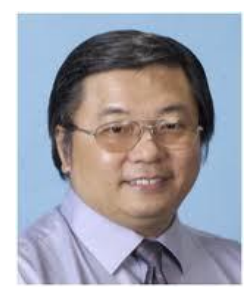

Chun Che Fung (Lance) was born in Hong Kong. He received a Bachelor of Science degree in Maritime Technology with First Class Honours and a Master of Engineering degree in System Test Technology from the University of Wales, Cardiff, UK in 1981 and 1982 respectively. He was then awarded a $\mathrm{PhD}$ degree in electrical engineering from the University of Western Australia in 1993. Lance has worked as a Lecturer at Singapore Polytechnic, and as a Senior Lecturer at Curtin University of Technology, Perth, Western Australia. Currently, he is an Associate Professor at the School of Information Technology, Murdoch University, Perth, Western Australia. He has published over 300 articles in book chapters, journals and conference proceedings.

Prof. Fung is a senior member of IEEE and a member of the Australian Computer Society (ACS). 